\title{
Malate Dehydrogenase Isolated from Extremely Halophilic Bacteria of the Dead Sea. 2. Effect of Salt on the Catalytic Activity and Structure ${ }^{\dagger}$
}

\author{
Moshe Mevarech and Eberhard Neumann*
}

ABSTRACT: The enzymatic activity and structural stability of the extremely halophilic enzyme malate dehydrogenase (EC 1.1.1.37) isolated from Dead Sea halobacteria depend in a different way on the concentration of inorganic salts. At low salt concentration ( $<2.0 \mathrm{M} \mathrm{NaCl}$ ) the enzyme is inactivated in a first-order reaction. When the salt concentration is increased the inactivated enzyme is reactivated in a second-order reaction. The inactivation at low salt concentration is ascribed to dissociation of the dimeric enzyme to inactive subunits and the reactivation at high salt concentration is determined by the rate of reassociation of the subunits to dimers. At low salt concentrations another process participates which causes an apparently irreversible (first order) denaturation. The rate

$\mathrm{E}$ xtremely halophilic bacteria are organisms which grow in saturated $\mathrm{NaCl}$ solutions and thus constitute a fascinating example of biological adaptation. It was reported that the internal salt concentration in bacteria of the genus Halobacterium is about $4 \mathrm{M} \mathrm{KCl}$ and $1.5 \mathrm{M} \mathrm{NaCl}$ (Ginzburg et al., 1971; Christian and Waltho, 1962). Besides the tolerance of high salt levels, halobacteria vary the intracellular salt content in response to changes in the environmental conditions. The halobacteria of the Dead Sea change the $\mathrm{NaCl}$ content between $3 \mathrm{M}$ during the growing phase and $0.5 \mathrm{M}$ under starvation conditions (Ginzburg et al., 1971). Obviously, the biochemical machinery of these bacteria including the enzymes is adapted not only to extremely high salt concentration but also to appreciable changes in the internal salt content. As a correlate, the catalytic activity of the isolated enzymes depends strongly on the salt concentration (Baxter and Gibbons, 1956; Holmes and Halvorson, 1965). At salt concentrations lower than $2.0 \mathrm{M}$ most of the halophilic enzymes studied are not stable and spontaneously inactivate (Lanyi, 1974). Whereas some quantitative studies have been performed on the inactivation of halophilic enzymes (Hochstein and Dalton, 1973; Holmes and Halvorson, 1965), reactivation studies have remained on a qualitative level (Hubbard and Miller, 1970; Keradjopoulos and Wulff, 1974).

One of the reasons for the small number of detailed biochemical and biophysical investigations on halophilic enzymes is encountered in the difficulty of purifying these enzymes. Recently, an efficient procedure has been developed for the purification to homogeneity of considerable amounts of the halophilic enzyme malate dehydrogenase of Dead Sea halobacteria (Mevarech et al., 1977). Initial physicochemical studies showed that the molecular weight of the active enzyme

\footnotetext{
† From the Polymer Department, Weizmann Institute of Science, Rehovot, Israel (M.M.), and Max-Planck-Institut für Biochemie, D8033 Martinsried bei München, West Germany (E.N.). Received January 20, 1977. This work was supported by a grant from the Stiftung Volkswagenwerk.
}

constants of the inactivation and reactivation processes depend in a characteristic manner on salt concentration and salt type $\left(\mathrm{NaCl}, \mathrm{KCl}, \mathrm{NH}_{4} \mathrm{Cl}\right.$, and $\left.\left(\mathrm{NH}_{4}\right)_{2} \mathrm{SO}_{4}\right)$, and on temperature. The thermodynamic analysis suggests that at concentrations below $0.15 \mathrm{M}$ the salt mainly screens the fixed charges of the subunits, whereas at concentrations higher than $0.8 \mathrm{M}$ the salt dominantly stabilizes hydrophobic interactions between the enzyme subunits. If the $\mathrm{NaCl}$ concentration is varied in a cyclic manner, the enzymatic activity changes along a hysteresis loop. This observation indicates relatively long-lived metastable states, reflected in the extremely small values of the rate constants of both the inactivation and reactivation process in the range of $\mathrm{NaCl}$ concentration where hysteresis exists.

is 84000 and that the enzyme is composed of two subunits. The amino acid composition indicated a very high negative net charge. In the present study a method is proposed to separate the effect of salt concentration and salt type on the catalytic activity from that on the structural stability of the enzyme. As a peculiar result, we note that in a certain concentration range the enzymatic activity displays relatively long-lived metastable states that result in a hysteresis loop upon cyclic variation of the salt concentration.

\section{Materials and Methods}

Chemicals. For the enzyme assay, oxaloacetic acid and $\mathrm{NADH}^{1}$ (Sigma) were used. All salts employed were of analytical grade.

Solutions. All solutions contain, in addition to the desired amounts of salt, $10 \mathrm{mM}$ sodium phosphate. The standard buffer solution contains $4.26 \mathrm{M} \mathrm{NaCl}, 0.01 \mathrm{M}$ sodium phosphate. The $\mathrm{pH}$ of all solutions was adjusted to 7.3 (Metrohm pH meter, Model E-300B, Metrohm EA $120 \mathrm{U}$ combined glass electrode).

All solutions were filtered through $0.45-\mu \mathrm{m}$ Millipore filters.

Enzyme Preparation and Assay. The purification of the halophilic enzyme malate dehydrogenase of Dead Sea halobacteria has been previously described (Mevarech et al., 1977).

Enzymatic activity was measured in $1 \mathrm{~mL}$ of the standard buffer containing, additionally, $0.1 \mathrm{mM} \mathrm{NADH}$ and $0.25 \mathrm{mM}$ oxaloacetate. The oxidation of NADH was followed at $340 \mathrm{~nm}$ with a Zeiss PMQ II spectrophotometer equipped with a linear-to-log converter and a recorder. Enzymatic activity is expressed in international units (IU).

Fluorescence Intensity Measurements. The changes in the intrinsic fluorescence of the enzyme were determined by using an Aminco Bowman spectrofluorometer. The excitation and

1 Abbreviation used: NADH, reduced nicotinamide adenine dinucleotide. 


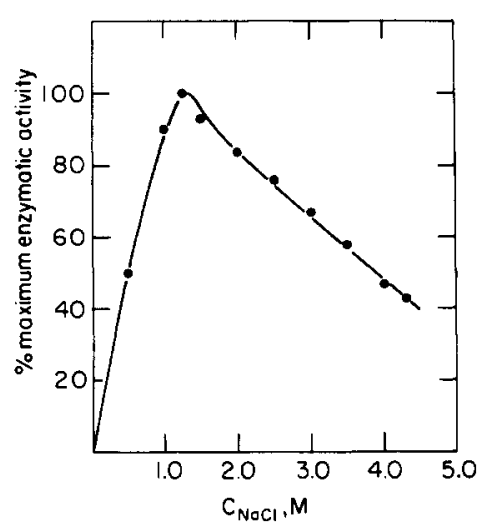

FIGURE 1: The enzymatic activity, relative to its maximum value, of malate dehydrogenase (MDH) from Dead Sea halobacteria, as a function

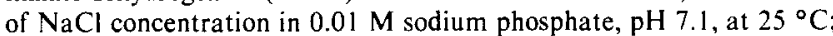
assays were performed at the indicated salt concentrations (and not under standard conditions; see text).

emission wavelengths were 290 and $325 \mathrm{~nm}$, respectively. The temperature in the measuring cell was controlled by a thermostated cell holder.

\section{Results}

Under conditions where NADH and oxaloacetate are in large excess to the enzyme, the initial rate, $v_{0}$, of $\mathrm{NADH}$ oxidation, is found to obey the relationship

$$
v_{0}=K\left[\mathrm{E}_{\mathrm{a}}\right]
$$

In eq $1,\left[E_{a}\right]$ is the concentration of the active enzyme and $K$ is a proportionality constant which contains combinations of elementary rate constants of the various steps in the enzymatic reaction (Dalziel, 1957). Since $K$ comprises rate constants for interactions between charged molecules, this rate parameter depends on the ionic strength of the solution. The concentration of the active enzyme, $\left[\mathrm{E}_{\mathrm{a}}\right]$, will depend on salt concentration, $C_{\mathrm{s}}$, if variations of $C_{\mathrm{s}}$ cause transitions between active and inactive enzyme states. Thus, we may write in general

$$
\frac{\mathrm{d} v_{0}}{\mathrm{~d} C_{\mathrm{s}}}=K\left(\frac{\mathrm{d}\left[\mathrm{E}_{\mathrm{a}}\right]}{\mathrm{d} C_{\mathrm{s}}}\right)+\left[\mathrm{E}_{\mathrm{a}}\right]\left(\frac{\mathrm{d} K}{\mathrm{~d} C_{\mathrm{s}}}\right)
$$

The first term on the right-hand side of eq 2 measures the dependence of the stability of the active enzyme on the salt concentration; the second term expresses the dependence of the enzymatic activity on the salt concentration.

Dependence of the Enzymatic Activity on $\mathrm{NaCl}$ Concentration. In order to measure the enzymatic activity at various salt concentrations, the enzyme in $4.3 \mathrm{M} \mathrm{NaCl}$ solution was diluted into solutions containing the substrates and having the desired salt concentration. The enzymatic activity was measured during the first minute immediately after dilution. It was found that under these conditions the enzyme is apparently not inactivated even at the lowest ionic strength applied. This is mainly due to the low inactivation rates in the presence of NADH (unpublished results). Thus, following this procedure, $\left[\mathrm{E}_{\mathrm{a}}\right]$ remains constant. For this case we may therefore reduce eq 2 to

$$
\frac{\mathrm{d} v_{0}}{\mathrm{~d} C_{\mathrm{s}}}=\left[\mathrm{E}_{\mathrm{a}}\right]\left(\frac{\mathrm{d} K}{\mathrm{~d} C_{\mathrm{s}}}\right)
$$

With eq 3 , the rate parameter $K$ can be determined as a function of salt at constant concentration of active enzyme. The enzymatic activities at $25^{\circ} \mathrm{C}$, measured at different $\mathrm{NaCl}$ concentrations (and not under the standard conditions of 4.3

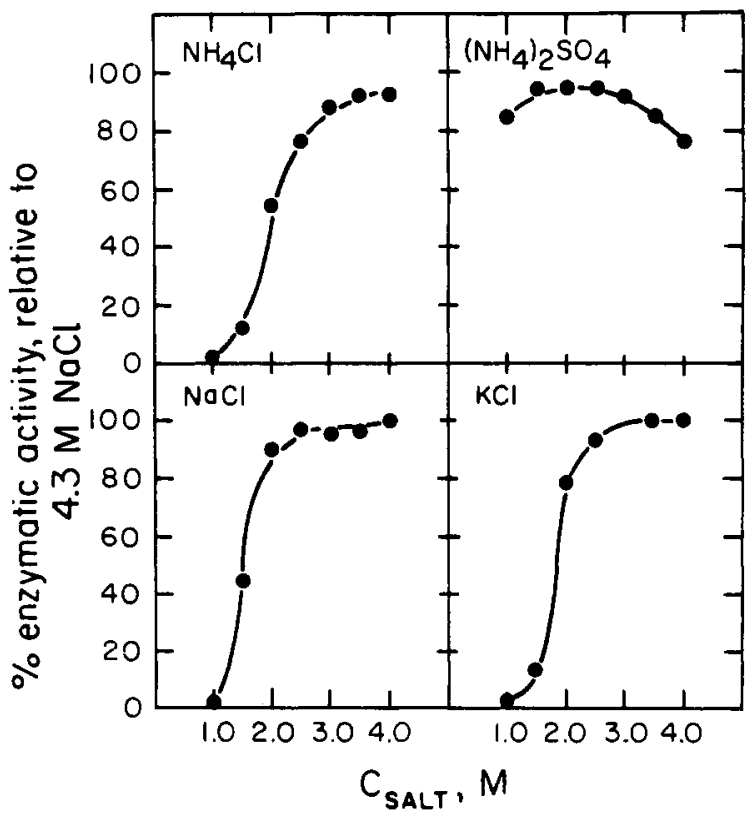

FIGURE 2: The salt dependence of the enzymatic activity (reflecting the structural stability) of MDH. After exposure to the indicated salt concentrations for $9 \mathrm{~h}$ at $30^{\circ} \mathrm{C}$, enzymatic activities were measured under

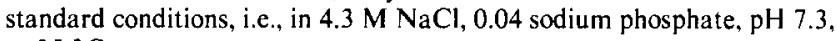
at $25^{\circ} \mathrm{C}$.

$\mathrm{M} \mathrm{NaCl}$ ), are presented in Figure 1. It is seen that an activity maximum occurs at about $1.25 \mathrm{M} \mathrm{NaCl}$.

Dependence of the Stability of the Active Enzyme on Salt Type and Concentration. In order to explore the effect of the salt type and salt concentration on the stability of the active enzyme, the enzymatic activity was determined under standard assay conditions after exposure of the enzyme to various salt concentrations.

The results of the inactivation-reactivation kinetics (next section) show that the enzyme transitions between the active form, $\mathrm{E}_{\mathrm{a}}$, and the inactive form, $\mathrm{E}_{\mathrm{i}}$, in this salt range are very slow as compared to the time of assay. Therefore, the distribution of the enzyme between the active and the inactive states in the standard assay solution is to a good approximation the same as that after the preequilibration to the various salt concentrations. For this case, eq 2 reduces to

$$
\frac{\mathrm{d} v_{0}}{\mathrm{~d} C_{\mathrm{s}}}=K\left(\frac{\mathrm{d}\left[\mathrm{E}_{\mathrm{a}}\right]}{\mathrm{d} C_{\mathrm{s}}}\right)
$$

and a change in $v_{0}$ reflects a change in the concentration of the active enzyme at constant rate parameter $K$. Figure 2 shows the relative activities of the enzyme measured under standard conditions $(4.3 \mathrm{M} \mathrm{NaCl})$ as a function of the various salts and concentration of the preincubation medium.

Kinetics of Enzyme Inactivation. (a) Enzymatic Activity. Aliquots of the enzyme stock solution at $4.3 \mathrm{M}$ were diluted to obtain solutions of different salts and concentrations and kept at constant temperature. At different times, $t$, after dilution, aliquots were transferred into standard assay solution. It was found that at salt concentrations lower than $2.0 \mathrm{M} \mathrm{NaCl}$ there is practically no reactivation. Thus, the inactivation occurs apparently irreversibly in this salt range. As suggested by the reactivation kinetics, the inactivation probably involves a dissociation of the dimeric enzyme into the two subunits. Thus,

$$
\mathrm{E}_{\mathrm{a}} \stackrel{k_{\mathrm{i}}}{\longrightarrow} 2 \mathrm{E}_{\mathrm{i}}
$$

and $k_{\mathrm{i}}=-\mathrm{d} \ln \left[\mathrm{E}_{\mathrm{a}}\right] / \mathrm{d} t$. The dependence of $\log k_{\mathrm{i}}$ on the 
TABLE I: Arrhenius Activation Energies, $A$, for the Inactivation of MDH at Various NaCl Concentrations.

\begin{tabular}{|c|c|c|c|c|c|c|c|c|}
\hline$C_{\mathrm{NaCl}}(\mathrm{M})$ & 0.1 & 0.3 & 0.59 & 0.85 & 1.09 & 1.31 & 1.55 & 1.8 \\
\hline$A\left(\mathrm{~kJ} \mathrm{~mol}^{-1}\right)$ & 64.4 & 112.9 & 140.9 & 120 & 153 & 185.6 & 192.3 & 199.8 \\
\hline
\end{tabular}

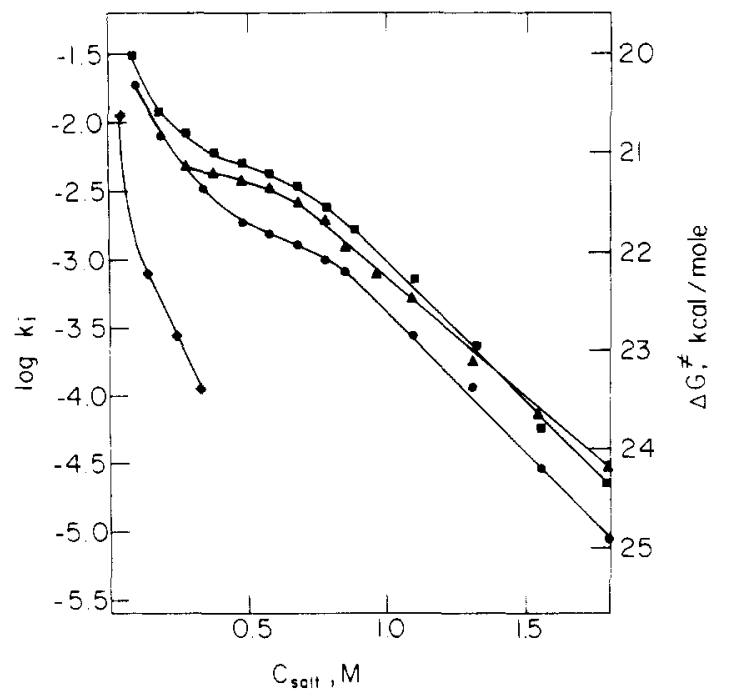

FGURE 3: The dependence of the decadic logarithm of the inactivation rate constant, $k_{i}\left(\mathrm{~s}^{-1}\right)$, as well as the free energy, $\Delta G^{\mp}$, calculated with eq 10 , on salt concentration, for the salts: (๑) $\left(\mathrm{NH}_{4}\right)_{2} \mathrm{SO}_{4},(\bullet) \mathrm{NaCl},(\Delta)$ $\mathrm{NH}_{4} \mathrm{Cl},(\mathbf{0}) \mathrm{KCl}$, at $30^{\circ} \mathrm{C}$.

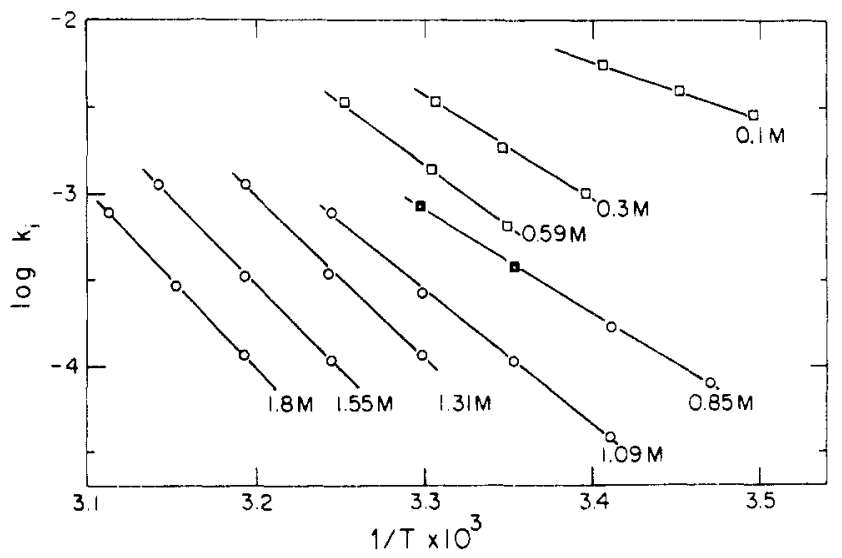

HGURE 4: Arrhenius representation of the inactivation rate constant, $k_{i}$, at the labeled concentration of $\mathrm{NaCl}(\square)$, measured by fluorescence intensity change; (O) measured by change in enzymatic activity; $T$, absolute temperature.

concentration of various salts, $\mathrm{NaCl}, \mathrm{KCl}, \mathrm{NH}_{4} \mathrm{Cl}$, and $\left(\mathrm{NH}_{4}\right)_{2} \mathrm{SO}_{4}$, is shown in Figure 3.

(b) Fluorescence Measurements. The inactivation process is accompanied by changes in the fluorescence spectrum (Mevarech et al., 1977). Thus, it is possible to follow the inactivation process by measuring the decrease of the intrinsic fluorescence with time. The analysis of the data is performed by using

$$
\ln \{F(t)-F(\infty)\}=\ln \{F(0)-F(\infty)\}-k_{\mathrm{i}}{ }^{\prime} t
$$

derived in Appendix I. In eq $6, F(t), F(\infty)$, and $F(0)$ are the fluorescence intensities at time $t$, at (infinite) time where no further change is observable and at time zero, respectively, $k_{\mathrm{i}}{ }^{\prime}$ is an apparent rate constant.

The time course of the fluorescence decay has been evaluated according to eq 6 . It has been found that for the same $\mathrm{NaCl}$ concentration and temperature the values of $k_{i}$ and $k_{i}{ }^{\prime}$

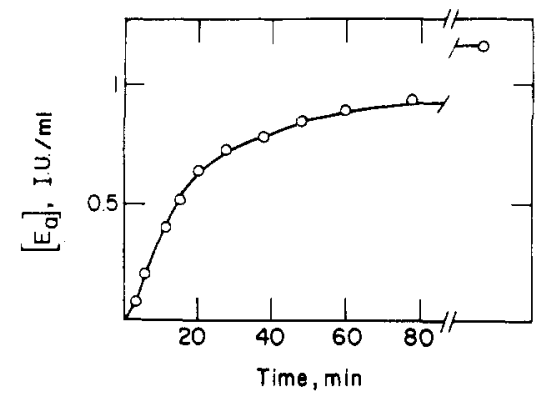

FIGURE 5: Reactivation kinetics of halophilic MDH. Concentration of the reactivated enzyme, $\left[E_{a}\right]$, at $2.86 \mathrm{M} \mathrm{NaCl}$ as a function of time, at 30 ${ }^{\circ} \mathrm{C}$. Initial concentration of inactivated enzyme $\left[\mathrm{E}_{\mathrm{a}}^{0}\right]=1.75 \times 10^{-\mathrm{x}}$ $\mathrm{M}$.

(eq 5 and 6) are the same (see Figure 4). This result indicates that the two methods for determining the rate of the inactivation process - the measurements of enzymatic activity and fluorescence intensity-are equivalent.

(c) Temperature Dependence of the Inactivation Process. The rate of inactivation depends strongly on the temperature. In Figure 4, the temperature dependence of $k_{i}$ at different salt concentrations is represented in "Arrhenius plots" according 10

$$
\ln k_{\mathrm{i}}=-\frac{A}{R T}+\mathrm{constant}
$$

where $A$ is the "activation energy" for the inactivation of the enzyme. In Table I, $A$ values for different $\mathrm{NaCl}$ concentrations are given.

Kinetics of Enzyme Reactivation. Catalytically active enzyme is first inactivated in low salt concentration and then the reactivation is started by diluting inactive enzyme into the desired salt solution at constant temperature. At various time intervals after dilution, aliquots were assayed at standard conditions. The reactivation process is followed until no further significant variation is observed $(\approx 12 \mathrm{~h})$. The experiments were performed at different initial enzyme concentrations and at different $\mathrm{NaCl}$ concentrations. A characteristic example for the reactivation kinetics is shown in Figure 5. The data can be analyzed in terms of a bimolecular association that occurs practically irreversibly under the given experimental conditions:

$$
2 \mathrm{E}_{\mathrm{i}} \stackrel{k_{\mathrm{r}}}{\rightarrow} \mathrm{E}_{\mathrm{i}}
$$

where $k_{\mathrm{r}}$ is the second-order reactivation rate constant.

The integral form of the second order equation for the reactivation process is (Appendix II) given by

$$
\frac{\left[\mathrm{E}_{\mathrm{a}}(t)\right]}{4\left[\mathrm{E}_{\mathrm{a}}^{\infty}\right]\left(\left[\mathrm{E}_{\mathrm{a}}^{\infty}\right]-\left[\mathrm{E}_{\mathrm{a}}(t)\right]\right)}=k_{\mathrm{r}} t
$$

In eq $8,\left[\mathrm{E}_{\mathrm{a}}(t)\right]$ and $\left[\mathrm{E}_{\mathrm{a}}^{\infty}\right]$ are, respectively, the concentration of the active enzyme at time $t$ and a time where no further reactivation occurs. When the reactivation is complete, $\left[\mathrm{E}_{\mathrm{a}}{ }^{\infty}\right]$ $=\left[E_{a}{ }^{0}\right]$, where $\left[E_{a}{ }^{0}\right]$ is the concentration of active enzyme prior to the inactivation by which $E_{i}$ was formed. It is found that eq 8 holds independent of the actual $\left[\mathrm{E}_{\mathrm{a}}{ }^{0}\right]$ values; see Figure 6. The dependence of $k_{\mathrm{r}}$ on $\mathrm{NaCl}$ concentration is shown in Figure 7. 


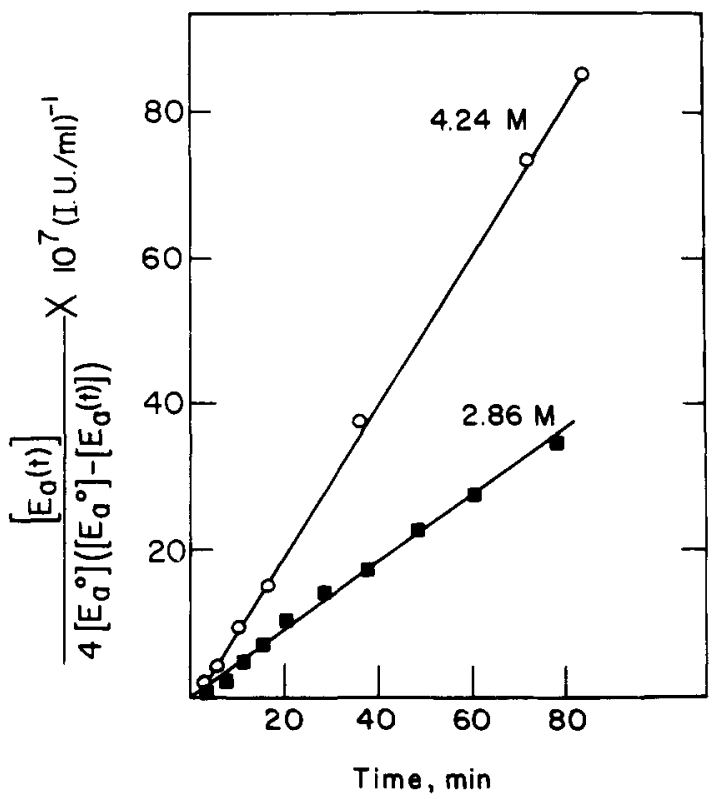

FIGURE 6: Analysis of the reactivation process in terms of eq 10 (see text); (O) $4.24 \mathrm{M} \mathrm{NaCl}$, (匹) $2.86 \mathrm{M} \mathrm{NaCl}, 30^{\circ} \mathrm{C}$. Initial concentration of inactivated enzyme $\left[\mathrm{E}_{\mathbf{a}}{ }^{0}\right]=1.75 \times 10^{-8} \mathrm{M}$.

Denaturation. When inactive enzyme is exposed for a long time to low salt concentrations, the amount of inactive enzyme that can be reactivated decreases with time. This process is apparently irreversible. In order to measure the rate of this irreversible process, active enzyme is inactivated at low salt concentration. At different intervals, aliquots were taken and reactivated by diluting into concentrated salt solutions. In all cases, the logarithm of the extent of maximum reactivation has been found to be a linear function of time. As an example, the half-lifetime for the denaturation process at $0.8 \mathrm{M} \mathrm{NaCl}$ at 20 ${ }^{\circ} \mathrm{C}$ is $11 \mathrm{~h}$. Thus, the "denaturation rate" is considerably smaller than the rate with which the enzyme can be reactivated and inactivated.

Hysteresis. Due to the very small reaction rates in the intermediate salt concentration range $(1.5-2.75 \mathrm{M})$, changes in salt concentration cause only very slow transitions between the active and inactive states of the enzyme. It is possible to calculate from $k_{\mathrm{i}}$ and $k_{\mathrm{r}}$ the equilibrium distribution of the enzyme in the active and inactive states at different salt concentrations. If we measure the actual activity at a given enzyme concentration, for instance, after $3 \mathrm{~h}$ of exposure from $4.3 \mathrm{M}$ $\mathrm{NaCl}$ to various lower salt concentrations, we find activity values higher than the equilibrium values (see Figure 8 ). On the other hand, if we measure the actual activity $3 \mathrm{~h}$ after exposure of the same amount of enzyme, previously inactivated at low salt concentration, to various higher salt concentrations, we find activity values which are lower than the equilibrium values.

Obviously, the enzyme is able to pass through thermodynamically metastable states that are relatively long lived. Under the experimental conditions of $2.16 \mathrm{M} \mathrm{NaCl}$, the extent of the reactivation reaches more than $90 \%$ of the original activity value. Thus, a cyclic variation of the $\mathrm{NaCl}$ concentration in the time range of $3 \mathrm{~h}$ closes a hysteresis loop (Neumann, 1973).

\section{Discussion}

Enzymatic Activity and Salt Concentration. A comparison of Figures 1 and 2 and an inspection of eq 2 and 3 show that the salt concentration affects the catalytic activity in a different way than the stability of the active enzyme. Whereas a de-

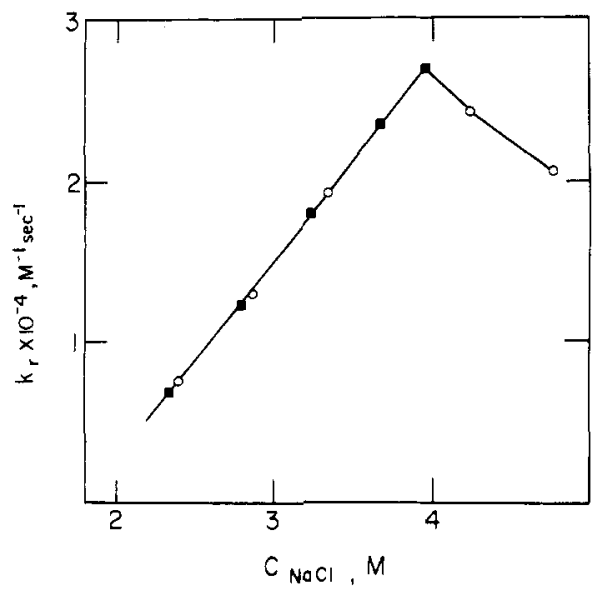

FIGLRE 7: Reactivation rate constants, $k_{\mathrm{r}}$, as a function of $\mathrm{NaCl}$ concentration, at $30^{\circ} \mathrm{C} .(\mathbf{m}, 0)$ Reactivation after complete inactivation in $0.86 \mathrm{M} \mathrm{NaCl}$ and in $0.43 \mathrm{M} \mathrm{NaCl}$, respectively.

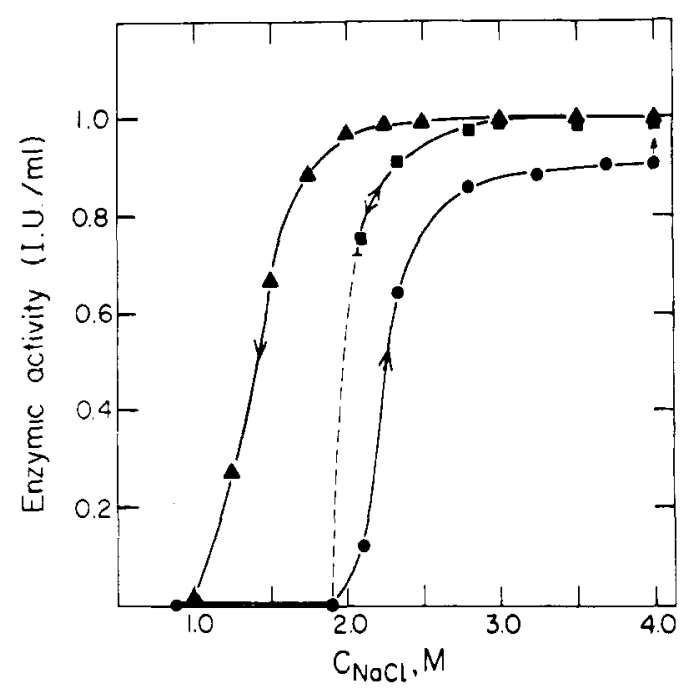

FIGURE 8: The enzymatic activity of MDH after exposure for $3 \mathrm{~h}$ to the indicated $\mathrm{NaCl}$ concentrations: $(\Delta) \mathrm{NaCl}$ concentration is decreased from $4.3 \mathrm{M},(-) \mathrm{NaCl}$ concentration is increased after $2 \mathrm{~h}$ of inactivation at $0.86 \mathrm{M} \mathrm{NaCl},(\mathbf{0})$ equilibrium values calculated from $k_{\mathrm{i}}$ and $k_{\mathrm{r}}$, at $30^{\circ} \mathrm{C}$ The cyclic variation of the $\mathrm{NaCl}$ concentration is associated with $\mathrm{a}(\mathrm{n})$ (almost) closed hysteresis loop.

crease in salt concentration decreases the structural stability, the enzymatic activity passes through a maximum at $1.25 \mathrm{M}$ $\mathrm{NaCl}$ at $25^{\circ} \mathrm{C}$.

The experimental procedure of measuring the activity as a function of salt concentration (Figure 1) excludes that major changes (like denaturation) in the enzyme structure are responsible for the maximum. Therefore, the maximum in $v_{0}$ is apparently caused by the salt dependence of the rate parameters of the elementary steps in the enzymatic catalysis; minor conformational changes induced by changing the salt concentration may, however, be involved. A change in salt concentration, for instance, may change the rate constants for the association-dissociation process between the enzyme and the reactants as well as the conversion of the substrates into products.

Since the reaction partners are charged species, the rate constants for the association-dissociation processes are a characteristic function of the thermodynamic activity coefficients of the reaction partners (Brönsted, 1922). If the intermolecular processes are rate determining, the overall reaction rate will pass through an extreme value at about the same salt 
concentration where the activity coefficients of the reaction partners have a minimum. The activity coefficients of many charged molecules in $\mathrm{NaCl}$ solution have a minimum value at about $1 \mathrm{M} \mathrm{NaCl}$ (Harned and Owen, 1967). Because the enzymatic activity shows a maximum close to the minimum of the activity coefficients, the observed salt dependence probably arises from an intermolecular rate-limiting step.

Structural Stability and Salt Concentration. The observation that halophilic enzymes require high salt concentrations in order to maintain their active structure led to the suggestion that the stabilizing effect of the salt is based on charge screening of the high net charge of the enzyme (Baxter and Gibbons, 1956). It is now recognized that, particularly at high salt concentrations, hydrophobic interactions may be more important for the stability of haloenzymes (Lanyi, 1974). It is known that an increase in the salt concentration increases the activity coefficients of nonpolar molecules (Edsall and Wyman, 1958); therefore, interactions between the nonpolar side groups of a protein are certainly more enhanced at high salt concentrations.

Because the halophilic malate dehydrogenase is a dimer, the inactivation in low salt concentration could result either from a conformational change within the dimer or from a dissociation of the dimer into the two subunits, or both. In order to differentiate between these alternatives, the kinetics of the inactivation (in low salt concentration) and of the reactivation (in high salt concentration) has been analyzed.

Inactivation Kinetics. Since the reactivation kinetics is clearly of second order, the inactivation must be coupled to the subunit dissociation. The dissociation process is certainly not an all-or-none reaction but, on an elementary scale, a stepwise decoupling of contact sites between the monomeric subunits, M. If we adopt an Eyring-like model (see, e.g., Johnson et al., 1954) for the macromolecular complex of the enzyme, we may postulate that, preceding the actual subunit separation, the dimer, D, passes through a series of "activated" states, $\mathrm{D}^{\ddagger}$. Assuming rapid equilibration for these intermediate forms, the rate constant $k_{\mathrm{i}}$ for the inactivation process

$$
\mathrm{D} \stackrel{(\bar{K})}{\rightleftharpoons} \mathrm{D}^{\mp} \stackrel{\left(k_{\mathrm{s}}\right)}{\longrightarrow} 2 \mathrm{M}
$$

can be written:

$$
k_{\mathrm{i}}=\bar{K} k_{\mathrm{s}}
$$

where $\bar{K}$ is the overall equilibrium constant for the intramolecular equilibrations $\mathrm{D} \rightleftharpoons \mathrm{D}^{\mp}$ associated with the standard free-energy change $\Delta G^{\circ}$, and $k_{\mathrm{S}}$ is the rate constant for the separation reaction. Within the framework of the Eyring model, where $k_{\mathrm{s}}$ is equal to the universal breakdown rate $k T / h$ ( $k$, Boltzmann constant; $h$, Planck constant; $T$, absolute temperature) and $\Delta G^{\circ}=\Delta G^{\ddagger}$ (the free-energy change for the formation of the activated states), we obtain

$$
\Delta G^{\neq}=R T \ln \left(k T / h k_{\mathrm{i}}\right)
$$

It is thus possible to estimate $\Delta G^{\neq}$from the measured $k_{\mathrm{i}}$ values.

The overall term $\Delta G \neq$ may be decomposed into two main contributions

$$
\Delta G^{\neq}=\Delta G_{\mathrm{el}}^{\neq}+\Delta G_{\text {so }}^{\neq}
$$

where $\Delta G^{\ddagger}$ el measures the difference in the electrostatic free energy between $\mathrm{D}$ and $\mathrm{D}^{\mp}$; the salting-out term $\Delta G^{\ddagger}$ so accounts for all nonelectrostatic contributions, including van der Waals and hydrogen-bond interactions.

Since the two subunits carry electrical charges, they tend to repel each other. Increasing salt concentration decreases by screening the repulsion between the fixed (surface) charges of the subunits. However, due to the high fixed charge density, the enzyme may be considered as a globular polyelectrolyte (Mevarech et al., 1977). Thus, already at low ionic strength $(<0.3 \mathrm{M})$ the screening of the surface charge by the ionic atmosphere is almost complete (Edsall et al., 1950); further increase in the jonic strength will affect only the remaining small effective charge. The change in the electrostatic contribution arising from a change in salt concentration may be estimated by using various models (Timasheff, 1970). It is found that this contribution is indeed small for ionic strengths $>0.15 \mathrm{M}$. Furthermore, $\Delta G^{\ddagger}{ }_{\text {el }}$ becomes almost constant when the ionic strength reaches $1.0 \mathrm{M}$.

If in the states $D^{\neq}$the majority of the interactions between the side chains of the amino acid residues and the hydrogen bonds between peptide bonds are disrupted, exposure to solvent leads to interactions with the salt ions. The free-energy changes associated with the exposure to the solvent of the amino acid residues at the contact area between the two subunits may be treated according to "salting out" theories (Schrier and Schrier, 1967; von Hippel and Hamabata, 1973), where the effect of salt on interactions between model compounds may be estimated by summing the individual contribution of the various functional groups. Also, in the case of halophilic $\mathrm{MDH}$, the magnitude of the total effect is expected to depend on the amino acid composition at the contact area between the two subunits, as well as on the type and concentration of the salt. Furthermore, the free-energy change of salting-out, $\Delta G_{\mathrm{so}}$, is linearly dependent on the salt concentration (Schrier and Schrier, 1967; Robinson and Jencks, 1965); thus,

$$
\mathrm{d} \Delta G_{\mathrm{so}} / \mathrm{d} C_{\mathrm{s}}=\text { constant }
$$

In the Eyring approximation of the inactivation kinetics of malate dehydrogenase, $\Delta G^{\neq}$is linearly dependent on $\log k_{j}$; cf. eq 10. As seen in Figure 4, the dependence of $\Delta G^{\neq}$on salt concentration is rather complicated. The salt dependence in the concentration range $\leqslant 0.2 \mathrm{M}$ may, however, be treated as a simple ionic-strength effect, independent of salt type. This supports the suggestion that at lower salt concentrations the electrostatic term $\Delta G^{\ddagger}{ }_{\mathrm{el}}$ is dominant.

It is readily seen that at salt concentrations higher than 0.85 $\mathrm{M}$ (measured up to $1.8 \mathrm{M}$ ), $\Delta G^{\ddagger}$ depends linearly on the salt content. It appears therefore that in accordance with the salting-out theory, the main contribution to the salt dependence of $\Delta G^{\mp}$ in this concentration range arises from the salting-out term $\Delta G^{\ddagger}{ }_{\text {so }}$. An estimate for the effectiveness of different salts to promote salting out may be derived by applying eq 11 to the results in Figure 3. The slopes of the $\Delta G^{\mp}$ vs. $C_{\text {s }}$ plots show that for the same anion $\mathrm{Cl}^{-}, \mathrm{K}^{+}$, and $\mathrm{Na}^{+}$ions have practically equal effectiveness and that the $\mathrm{NH}_{4}{ }^{+}$ion is slightly less effective. The largest slope, however, is associated with $\left(\mathrm{NH}_{4}\right)_{2} \mathrm{SO}_{4}$ and it is well known that this salt is most effective for salting-out reactions.

For the intermediate salt range, $0.15-0.85 \mathrm{M}$, the dependence of $\Delta G^{\ddagger}$ on $C_{\mathrm{s}}$ indicates a transition range (Figure 3 ). It appears that in this region an additional salt-dependent process is present. Probably a structural (conformational) change of the enzyme accompanies the salt type and concentrationdependent phenomena discussed above. This suggestion is supported by the observation that in the same salt concentration range the Arrhenius activation energy for the inactivation process passes through a maximum at $0.59 \mathrm{M} \mathrm{NaCl}$, decreases until $C_{\mathrm{s}}=0.85 \mathrm{M} \mathrm{NaCl}$, and then increases again (see Table I). This behavior is very suggestive for the participation of structural transitions accompanying the inactivation process in this salt range. 
Reactivation Kinetics. The rate-limiting step in the reactivation kinetics is bimolecular, as discussed for the data in Figure 6. However, there is a small "delay phase" which is clearly visible for lower salt concentrations of the reactivation medium; see the data for $2.86 \mathrm{M}$ in Figure 6 . In order to account for this delay phase, we may assume that after the production of $M$ from $D$ the monomer is further changed to a different form $M^{*}$ which is more stable at low salt concentration. When the inactive enzyme is now transferred to high salt concentration, there is first an intramolecular transition $M^{*} \rightarrow M$ and only then $D$ can be produced.

In the salt concentration range where the reactivation process can be readily followed $\left(C_{\mathrm{S}} \geqslant 2.4 \mathrm{M}\right)$, the rate constant $k_{\mathrm{r}}$ increases linearly with the salt content and reaches a maximum about $4 \mathrm{M}$ (see Figure 7). Despite the linearity, there is at present no simple analysis for the observed $k_{\mathrm{r}}$ values. However, it is possible that at concentrations above $4 \mathrm{M}$ structurally "wrong" dimers are relatively stable and thus the production rate of "correct" dimers decreases.

Reaction Scheme. The present data on the salt-dependent inactivation and reactivation processes suggest as a minimum reaction scheme:

$$
\mathrm{D} \underset{k_{\mathrm{r}}}{\stackrel{k_{\mathrm{i}}}{\underset{ }{\longrightarrow}}} 2 \mathrm{M} \rightleftharpoons 2 \mathrm{M}^{*} \longrightarrow 2 \mathrm{M}_{\mathrm{d}}
$$

At salt concentrations higher than about $2 \mathrm{M}$, the dimer, D, is the most stable state for the catalytically active enzyme. The reduction of the salt concentration leads (possibly via intermediate $\mathrm{D}^{\ddagger}$, see eq 9) to catalytically inactive monomers, $M$. The lag phase observed in the reactivation kinetics is tentatively accounted for by the salt-dependent equilibrium $\mathrm{M} \rightleftharpoons \mathrm{M}^{*}$. At low salt concentration $(\leqslant 1.0 \mathrm{M})$ a very slow, apparently irreversible denaturation occurs $\left(\mathrm{M}^{*} \rightarrow \mathrm{M}_{\mathrm{d}}\right)$. The curved arrows in the scheme are to indicate that the salt-induced transitions between active dimers and inactive monomers may proceed via relatively long-lived metastable states. At present it is not possible to specify a physiological significance for these metastable states which cause the hysteresis in the inactivationreactivation cycle (see Figure 8 ). According to Katchalsky, hysteresis in chemodiffusional flow coupling is a mechanism for converting a stationary flow into an oscillatory concentration change of reaction components (Katchalsky and Spangler, 1968; see also Neumann, 1973). It is yet an open question whether the long-lived metastable states in the halophilic malate dehydrogenase are correlated with mechanisms to which halophilic enzymes in general have adapted under conditions of very high salt concentrations.

\section{Acknowledgments}

The early steps of this study were initiated under the guidance and inspiration of Aharon Katchalsky (1913-1972). Parts of the work were carried out at the Max-Planck-Institut für biophysikalische Chemie, Göttingen. We thank Professors Manfred Eigen and Henryk Eisenberg for critical discussions.

\section{Appendix I}

Assuming additivity of the fluorescence intensities of the active enzyme $\mathrm{E}_{\mathrm{a}}$ and the inactive enzyme $\mathrm{E}_{\mathrm{i}}$, we obtain for the total fluorescence intensity, $F(t)$, at any time, $t$,

$$
F(t)=F_{\mathrm{a}}\left[\mathrm{E}_{\mathrm{a}}(t)\right]+0.5 F_{\mathrm{i}}\left[\mathrm{E}_{\mathrm{j}}(t)\right]
$$

where $F_{\mathrm{a}}$ and $F_{\mathrm{i}}$ are constants accounting for the specific contributions at $\left[\mathrm{E}_{\mathrm{a}}\right]=1 \mathrm{M}$ and $\left[\mathrm{E}_{\mathrm{i}}\right]=1 \mathrm{M}$ to $F(t)$, respectively. According to conservation of mass, we have

$$
\left[\mathrm{E}^{0}\right]=\left[\mathrm{E}_{\mathrm{a}}(t)\right]+0.5\left[\mathrm{E}_{\mathrm{i}}(t)\right]
$$

where $\left[E^{0}\right]$ is the initial enzyme concentration (dimer). Introducing $\left[E_{a}(t)\right]$ from eq $I .2$ into eq $I .1$ and using eq 5 of the text, one obtains after integration

$$
\ln \left\{F(t)-F_{\mathrm{i}}\left[\mathrm{E}^{0}\right]\right\}=\ln \left\{\left(F_{\mathrm{a}}-F_{\mathrm{i}}\right)\left[\mathrm{E}^{0}\right]\right\}-k_{\mathrm{i}}{ }^{\prime} t
$$

If $\left[\mathrm{E}_{\mathrm{a}}\right] \rightarrow 0, F(t)$ becomes practically a constant, denoted by $F(\infty)$. Since the inactivation occurs practically irreversibly under the given experimental condition: $F(\infty)=F_{\mathrm{i}}\left[\mathrm{E}_{\mathrm{i}}(\infty)\right]=$ $F_{\mathrm{i}}\left[\mathrm{E}^{0}\right]$. At $t=0, F(0)=F_{\mathrm{a}}\left[\mathrm{E}^{0}\right]$. Inserting the expressions for $F(0)$ and $F(\infty)$ into eq 1.3 , we obtain eq 6 of the text.

\section{Appendix II}

The rate equation for the overall reaction

$$
2 \mathrm{E}_{\mathrm{i}} \underset{k_{\mathrm{i}}}{\stackrel{k_{\mathrm{r}}}{\rightleftharpoons}} \mathrm{E}_{\mathrm{a}}
$$

is given by

$$
\frac{\mathrm{d}\left[\mathrm{E}_{\mathrm{a}}\right]}{\mathrm{d} t}=k_{\mathrm{r}}\left[\mathrm{E}_{\mathrm{i}}\right]^{2}-k_{\mathrm{i}}\left[\mathrm{E}_{\mathrm{a}}\right]
$$

Under conditions where $k_{\mathrm{i}}$ is very small, eq II. 2 reduces to

$$
\frac{\mathrm{d}\left[\mathrm{E}_{\mathrm{a}}\right]}{\mathrm{d} t}=k_{\mathrm{r}}\left[\mathrm{E}_{\mathrm{i}}\right]^{2}
$$

According to mass conservation, $\left[E_{i}{ }^{0}\right]=\left[E_{i}\right]+2\left[E_{a}\right]$, where $\left[E_{i}{ }^{0}\right]$ is the total concentration of monomers. Eq II.3 can now be rewritten to

$$
\frac{\mathrm{d}\left[\mathrm{E}_{\mathrm{a}}\right]}{\left\{\left[\mathrm{E}_{\mathrm{i}}{ }^{0}\right]-2\left[\mathrm{E}_{\mathrm{a}}\right]\right\}^{2}}=k_{\mathrm{r}} \mathrm{d} t
$$

After integration using the boundary conditions at $t=0,\left[\mathrm{E}_{\mathrm{i}}\right]$ $=\left[\mathrm{E}_{\mathrm{i}}^{0}\right]$ and $2\left[\mathrm{E}_{\mathrm{a}}\right]=0$, we obtain

$$
\frac{\left[\mathrm{E}_{\mathrm{a}}(t)\right]}{\left[\mathrm{E}_{\mathrm{i}}^{0}\right]\left(\left[\mathrm{E}_{\mathrm{i}}^{0}\right]-2\left[\mathrm{E}_{\mathrm{a}}(t)\right]\right)}=k_{\mathrm{r}} t
$$

At time $(t \rightarrow \infty)$ where no further reactivation occurs, $\left[\mathrm{E}_{\mathrm{j}}{ }^{0}\right]$ is replaced by $2\left[E_{a}{ }^{\infty}\right]$ and, for the case that not all of the inactivated enzyme can be reactivated, we obtain eq 8 of the text.

\section{References}

Baxter, R. M., and Gibbons, N. E. (1956), Can. J. Microbiol. 2, 599.

Brönsted, J. N. (1922), Z. Phys. Chem., Abt A 102, 169.

Christian, J. H. B., and Waltho, J. A. (1962), Biochim. Biophys. Acta 65, 508.

Dalziel, K. (1957), Acta Chem. Scand. 11, 1706.

Edsall, J. T., Edelhoch, H., Lontie, R., and Morrison, P. R. (1950), J. Am. Chem. Soc. 72, 4641 .

Edsall, J. T., and Wyman, J. (1958), Biophysical Chemistry, Vol. 1, New York, N.Y., Academic Press, p 263.

Ginzburg, M., Sachs, L., and Ginzburg, B. Z. (1971), J. Membr. Biol. 5, 78.

Harned, H. S., and Owen, B. B. (1967), The Physical Chemistry of Electrolytic Solutions, 3rd ed, New York, N.Y., Reinhold, p 678.

Hochstein, L. I., and Dalton, B. P. (1973), Biochim. Biophys. Acta 302, 216.

Holmes, P. K., and Halvorson, H. O. (1965), J. Bacteriol. 90 , 316.

Hubbard, J. S., and Miller, A. B. (1970), J. Bacteriol. 102 677.

Johnson, F. H., Eyring, H., and Polissar, M. J. (1954), The Kinetic Basis of Molecular Biology, New York, N.Y., 
Wiley.

Katchalsky, A., and Spangler, R. (1968), Q. Rev. Biophys. 1. 127.

Keradjopoulos, D., and Wulff, K. (1974), Can. J. Biochem. $52,1033$.

Lanyi, J. K. (1974), Bacteriol. Rev. 38, 272.

Mevarech, M., Eisenberg, H., and Neumann, E. (1977),

Biochemistry 16 (preceding paper in this issue).

Neumann, E. (1973), Angew. Chem., Int. Ed. Engl. 12,
356.

Robinson, D. R., and Jencks, W. P. (1965), J. Am. Chem. Soc. $87,2470$.

Schrier, E. E., and Schrier, E. B. (1967), J. Phys. Chem. 71 , 1851.

Timasheff, S. N. (1970), in Biological Polyelectrolytes, Veis, A., Ed., New York, N.Y. Marcel Dekker, p 1.

von Hippel, P. H., and Hamabata, A. (1973), J. Mechanochem. Cell Motil. 2, 127.

\title{
Evidence for Induced Interactions in the Anticooperative Binding of Nicotinamide Adenine Dinucleotide to Sturgeon Muscle Glyceraldehyde-3-phosphate Dehydrogenase ${ }^{\dagger}$
}

\author{
J. W. Long ${ }^{\ddagger}$ and F. W. Dahlquist*.\$
}

\begin{abstract}
The tetrameric glyceraldehyde-3-phosphate dehydrogenase isolated from sturgeon muscle shows negative cooperativity in nicotinamide adenine dinucleotide (NAD) binding. After alkylation of each of the four active sites with the sulfhydryl reagent bromotrifluoroacetone, this cooperativity is abolished and the apparent affinity is weakened about tenfold. Fluorine magnetic resonance shows a single resonance which shifts upon the addition of NAD and indicates rapid chemical exchange of NAD between the free and bound states. Using two molecules of NAD per enzyme tetramer, it is possible to direct alkylation of half of the four sites. Fluorine magnetic resonance spectra of this derivative show no change
\end{abstract}

$\mathrm{T}_{\mathrm{h}}$ cooperative binding has received considerable attention in recent years. One of the most interesting aspects of this general question is the negative cooperativity exhibited by a number of dehydrogenases in the binding of their coenzyme and substrates. This phenomenon has been most thoroughly studied using glyceraldehyde-3-phosphate dehydrogenases $(G P D H)^{\prime}$ from many sources. In such systems nicotinamide adenine dinucleotide (NAD) has been shown to be a participant in the oxidation of glyceraldehyde 3-phosphate, an activator of the thio-acyl bond in at least some acyl-enzyme reactions (Schwendimann et al., 1976) and a regulator of enzyme activity as a result of its anticooperative binding to the enzyme (Conway and Koshland, 1968).

It has become clear that enzymes isolated from various sources display similar qualitative behavior with respect to the roles of NAD in catalysis and regulation. The quantitative aspects of this behavior vary greatly, however, from source to

\footnotetext{
† From the Institute of Molecular Biology, University of Oregon, Eugene, Oregon 97403. Received July 28, 1976; revised manuscript received May 13, 1977

¥ Present Address: Department of Natural Science, College of Great Falls, Great Falls, Montana 59405

$\$$ Alfred P. Sloan Fellow, 1975-1977.

'Abbreviations used are: GPDH, glyceraldehyde-3-phosphate dehydrogenase; NAD, nicotinamide adenine dinucleotide; NADH, reduced NAD; EDTA, (ethylenedinitrilo)tetraacetic acid; $\mathrm{Nbs}_{2}, 5,5^{\prime}$-dithiobis (2nitrobenzoic acid).
}

upon addition of up to two NAD molecules to the half-modified enzyme. These NAD molecules appear to bind to the nonalkylated active sites. Upon addition of between two and four molecules of NAD, two resonances are observed. The relative proportion of each varies linearly with NAD. This implies slow exchange of NAD on and off alkylated sites which are adjacent to unmodified NAD-bound sites. Since the kinetics of NAD exchange in half-alkylated material are clearly different from that observed in the fully alkylated enzyme, there appear to be induced interactions between subunits which are at least partially mediated by the active-site sulfhydryl residues.

source. This variability is most apparent when one considers the binding of NAD. The enzyme isolated from rabbit muscle shows a very dramatic negative cooperativity in its binding of NAD. The binding of the most tightly bound two NAD molecules to this enzyme is extremely strong with estimates of the affinity constants for these sites in the range of $10^{8}-10^{10} \mathrm{M}^{-1}$ (Conway and Koshland, 1968). The weaker two NAD binding sites have affinities in the range of $10^{5}-10^{6} \mathrm{M}^{-1}$. Thus, there is a several orders of magnitude difference in the apparent affinities of the strongest and weakest sites. The enzymes isolated from sturgeon or halibut also demonstrate a clear negative cooperativity in NAD binding, but only about a factor of 10 or less difference in apparent affinity of the strong and weak sites is observed (Seydoux et al., 1973). Yeast provide still another quantitative difference in the binding of NAD to their GPDH. In this case, the binding shows a mixture of apparent positive and negative cooperativity at room temperature and positive cooperativity at $37^{\circ} \mathrm{C}$ (Cook and Koshland, 1970; Kirschner et al., 1971).

In addition to the various kinds of cooperativity exhibited by the GPDs from different sources, all the enzymes appear to demonstrate half of the site reactivity with respect to certain kinetic parameters and active-site alkylation by certain sulfhydryl reagents (Seydoux et al., 1974). Two alternate models have been proposed to explain both half of the site reactivity and anticooperativity in ligand binding in the enzymes. One of these supposes that the enzyme consists of four subunits which are in identical conformations in the absence of any li- 